TP Periodica Polytechnica Chemical Engineering

62(2), pp. 195-201, 2018

https://doi.org/10.3311/PPch.10694

Creative Commons Attribution (i)

RESEARCH ARTICLE
Catalytic Activity of

\section{Maghnite- $\mathrm{H}^{+}$in the Synthesis of Polyphenylmethylsiloxane under Mild and Solvent-free Conditions}

\author{
Djamal Eddine Kherroub ${ }^{1,2^{*}}$, Mohammed Belbachir ${ }^{1}$, Saad Lamouri ${ }^{3}$, \\ Larbi Bouhadjar ${ }^{1}$, Karim Chikh ${ }^{1}$
}

Received 03 March 2017; accepted after revision 24 July 2017

\begin{abstract}
In this study, a new and easy strategy was discussed for the purpose of synthesizing of a polymer of phenylmethylcyclosiloxane type (PPMS). The cationic ring opening polymerization of triphenyltrimethylcyclotrisiloxane $\left(D_{3}^{P h, M e}\right)$ was initiated by a solid, efficient and environmentallyfriendly catalyst called Maghnite- $H^{+}$. Maghnite- $H^{+}$is a natural clay composed essentially of montmorillonite, it is activated with an acid treatment by replacing the interlayer ions by protons, that results to the increase of the basal space, this may be confirmed by XRD analysis. The reaction was carried out without solvent at different temperatures and for different periods of time, using also several catalyst contents. Subsequently, the operating conditions were opted in order to obtain a maximum yield of the linear polymer and a high average molecular mass as well. The structure of polymers obtained was confirmed by IR analysis. ${ }^{1} \mathrm{H} N M R$ and ${ }^{13} C N M R$ analyzes were used to follow the crosslinking of polymer chains over time. The thermal behavior was investigated by DSC analysis. The average molecular mass and the polydispersity indices were determined by GPC.
\end{abstract}

\section{Keywords}

maghnite, catalyst, ring opening polymerization, ecological, polyphenylmethylcyclosiloxane

\footnotetext{
${ }^{1}$ Department of Chemistry, Faculty of Exact and Applied Sciences, University of Oran 1 Ahmed Ben Bella, BP 1524 El'Menouer Oran 31000, Algeria

${ }^{2}$ Department of Process Engineering, Relizane Institute of Science and Technology,

University Centre of Relizane Ahmed Zabana BP 48000, Algeria

${ }^{3}$ Teaching and Research Unit, Algiers Polytechnic Military School, Bordj El Bahri, 16111 Algiers, Algeria

*Corresponding author, e-mail: djamaleddine.kherroub@yahoo.com
}

\section{Introduction}

The manufacture of more than $80 \%$ of chemicals depends on catalytic reactions. To create new products, or to use new raw materials, chemists must therefore develop new catalysts. In particular, one of the current challenges for chemistry is to replace the hazardous catalysts, strong acids and bases with various mineral or biomass compounds [1]. Clay minerals possess various properties have led to their use by chemists for a wide variety of applications, for example as a texture agent in paints, bleaching agent for paper, or a reinforcing agent for polymer-based plastics, they are also used in heterogeneous catalysis to initiate several chemical reactions. The heterogeneous catalysis makes it possible to demonstrate the reduction of the number of steps and the economy of atoms. In addition, it deals in the course of development, the stakes of enantioselective catalysis, in particular compared to the criteria of green chemistry $[2,3]$.

The objective of this work is based on heterogeneous catalysis using Maghnite, which makes it possible to carry out chemical reactions in order to synthesize silicone polymers at low temperature and in limited time. Maghnite is a natural Algerian clay obtained from the region of Maghnia that is located in the northwest of Algeria [4,5]. It is a new catalyst based on montmorillonite when activated with a strong acid. This catalyst was developed in Polymer Chemistry Laboratory «LCP», it has shown remarkable catalytic capabilities in polymerization reactions of various vinyl and heterocyclic monomers. Several studies have been carried out at the LCP concerning the introduction of Maghnite- $\mathrm{H}^{+}$in the initiation of polymerization reactions [6-8]. In other works, Maghnite has been used as an inorganic reinforcement and as an initiator at the same time in different reactions in order to synthesize nanocomposite materials [9-11]. In this case, we will study the possibility of using Maghnite- $\mathrm{H}^{+}$as a catalyst to obtain a new class of widely used polymers which are silicones.

The name silicone was given for the first time by Kipping in 1901 to describe compounds consisting of a sequence of silicon-oxygen units and organic side groups bound to the silicon atom (Scheme 1a). The most common example is 
polydimethylsiloxane [12,13]. Polydimethylsiloxane (PDMS) is the most commercially available siloxane polymer in the world. Despite the good characteristics of this material, such as high flexibility at low temperature, very high radiation resistance, higher thermal stability and refraction, some gaps persist $[14,15]$. Very often, these characteristics can be improved by the substitution of dimethylsiloxane units with those of phenylmethylsiloxane in the PDMS chain (Scheme 1b) $[16,17]$. The production of polyphenylmethylsiloxanes is usually carried out by anionic or cationic ring opening polymerization of triphenyltrimethylcyclotrisiloxane (Scheme 1c) [18-21]. They were obtained previously in the presence of strong bases as phosphazenebases [22-25],strongacidsasdodecylbenzenesulfonic acid [26], triflic acid [27], tris(pentafluorophenyl)borane [28] and trifluoromethanesulfonic acid [29], etc.

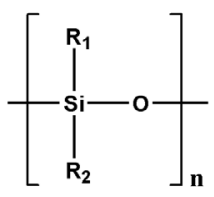

(a)

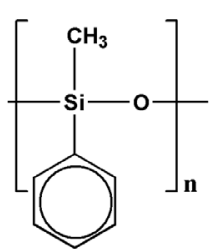

(b)

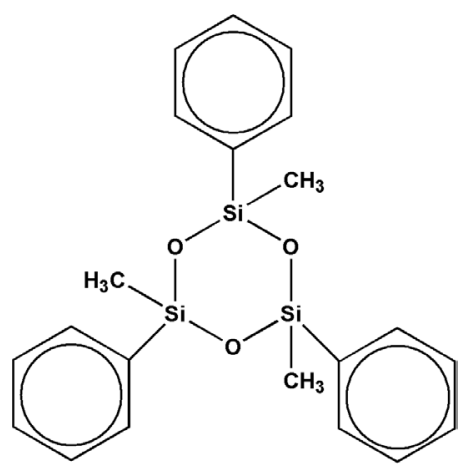

(c)
Scheme 1 The structure of (a) Silicone;

(b) Polyphenylmethylsiloxane and (c) $\mathrm{D}_{3}{ }^{\mathrm{Ph}, \mathrm{Me}}$

\section{Experimental}

\subsection{Materials}

Triphenyltrimethylcyclotrisiloxane $\left(\mathrm{D}_{3}^{\mathrm{Ph}, \mathrm{Me}}, 99 \%\right)$ was used as purchased from Aldrich chemical, without further purification. Methanol was purified by vacuum distillation. All other products have been used as received. Maghnite was obtained from Algerian company of bentonite (BENTAL), without any pretreatment.

\subsection{Preparation of Maghnite- $\mathrm{H}^{+}$}

A mass of $30 \mathrm{~g}$ of raw Maghnite is combined with $120 \mathrm{ml}$ of distilled water at room temperature, the suspension is left under stirring. After $30 \mathrm{~min}, 100 \mathrm{ml}$ of a solution of sulfuric acid $(0.23$ M) is added, the stirring is continued for $48 \mathrm{~h}$. After filtration and subsequent washing, the activated Maghnite is dried in an oven for $24 \mathrm{~h}$ at a temperature of $105^{\circ} \mathrm{C}$. Finally, Maghnite- $\mathrm{H}^{+}$ was crushed, sieved and stored away from air and moisture.

\subsection{Polymerization procedure}

$0.075 \mathrm{~g}$ of Maghnite- $\mathrm{H}^{+}$is heated before use under vacuum with mechanical stirring for $30 \mathrm{~min}$. The polymerization was carried in bulk. The dried amount of Maghnite- $\mathrm{H}^{+}$is added to a flask containing $5 \mathrm{~g}$ of $\mathrm{D}_{3}^{\mathrm{Ph}, \mathrm{Me}}$, the flask is immersed in an oil bath and brought to a temperature of $55^{\circ} \mathrm{C}$ at while being stirred. After $150 \mathrm{~min}$, the reaction was stopped by deactivating the Maghnite- $\mathrm{H}^{+}$by adding $1 \mathrm{ml}$ of cold water to the reaction mixture. The Maghnite- $\mathrm{H}^{+}$is recovered by filtration, and the filtrate is precipitated in methanol (non-solvent). The insoluble product was dried at $80{ }^{\circ} \mathrm{C}$ in vacuum for $3-4 \mathrm{~h}$ and weighed as polymer. It was assumed that the residual material is the remaining monomers and the oligomers formed during the reaction. Regarding the kinetic study, the same procedure described above was repeated by changing the temperature, time and the percentage of the catalyst.

\subsection{Characterization methods 2.4.1 X-ray Diffraction}

The XRD patterns of the samples were carried out at room temperature on a Bruker D8 Advance X-Ray diffractometer (40 kV, $30 \mathrm{~mA}$ ) with a graphite monochromator, using $\mathrm{CuK} \alpha$ radiation $(\lambda=0.154 \mathrm{~nm})$ at the rate of $5^{\circ} \mathrm{min}^{-1}$ in the range of $2 \theta=2^{\circ}$ to $80^{\circ}$.

\subsubsection{Infrared Spectroscopy}

Infrared analysis of the polymers obtained was done using a Bruker Alpha FT-IR spectrometer equipped with an ATR accessory.

\subsubsection{Nuclear Magnetic Resonance}

${ }^{1} \mathrm{H}$ and ${ }^{13} \mathrm{C}$ NMR spectra were recorded under ambient temperature on Bruker Avance 300 NMR spectrometer, using tetramethylsilane as internal standard and deuterated chloroform as solvent.

\subsubsection{Differential Scanning Calorimetry}

The different thermal characteristics such as $\mathrm{Tg}$ of the synthesized polymer were measured by DSC from the corresponding thermal changes in the DSC thermogram using a Setaram 92 DSC apparatus. The specimen (approximately $10 \mathrm{mg}$ ) is heated at a rate of $10{ }^{\circ} \mathrm{C} / \mathrm{min}$ from -100 to $150{ }^{\circ} \mathrm{C}$ under a nitrogen atmosphere. The spectrum presented was obtained after a second heating.

\subsubsection{Molecular Weight Measurements}

Gel permeation chromatography (GPC) measurements of the samples was performed using a WISP Model 712, Waters Associates chromatograph, THF was used as a solvent and the apparatus was calibrated in an initial approximation with poly(methyl methacrylate) of known molecular weight. 


\section{Results and Discussion}

\subsection{X-ray Diffraction (XRD)}

Fig. 1 shows the characterization by XRD analysis of the raw Maghnite and Maghnite treated with sulfuric acid. It is obvious that the treatment led to the removal of minerals such as Calcite and Mica, this is confirmed by the decline of the intensity of their peaks compared to the strong peak corresponding to montmorillonite (green area), this elimination is clearer for the quartz, as shown by the reduction of the two peaks at $2 \theta=21.93^{\circ}$ and $26.71^{\circ}$ (blue areas). Moreover, the acid treatment caused a shift of the peak of montmorillonite to small values of $2 \theta$ from $8.41^{\circ}$ to $5.73^{\circ}$, corresponding to an increase of the basal space of montmorillonite $\left(\mathrm{d}_{001}\right)$ from $10.50 \AA$ to $15.41 \AA$, this can be explained by the substitution of interlamellar cations of Maghnite by oxonium ions which have a larger atomic diameter.

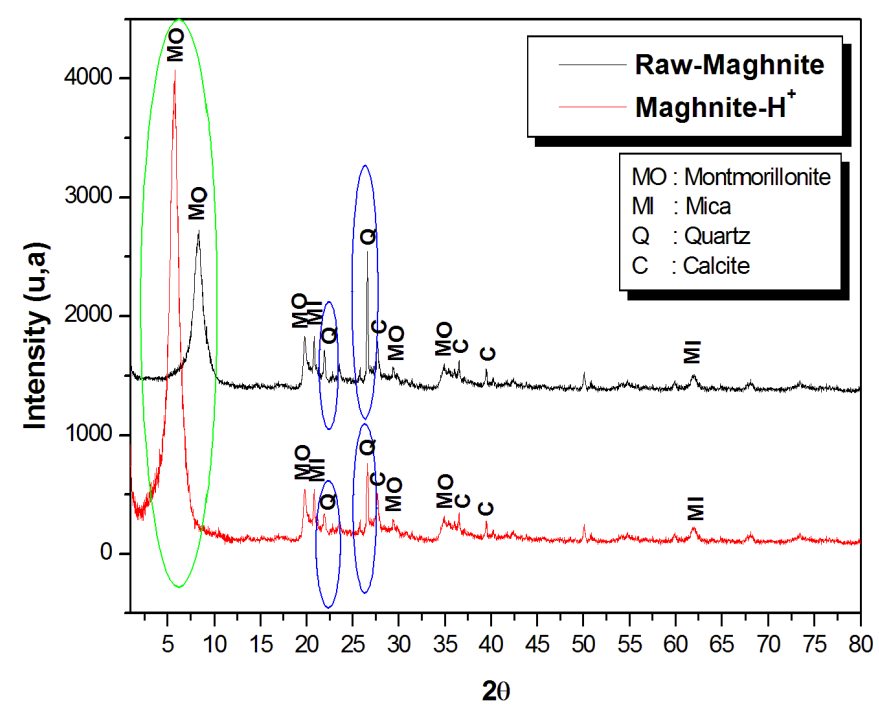

Fig. 1 XRD patterns of the Maghnite before treatment (Raw-Maghnite) and after treatment $\left(\right.$ Maghnite- $\left.\mathrm{H}^{+}\right)$

\subsection{Infrared Spectroscopy (IR)}

Fig. 2 provides the infrared spectra of the monomer and the obtained products for $90,120,150,180$ and $210 \mathrm{~min}$ at $55^{\circ} \mathrm{C}$. The broad peak seen at $3419 \mathrm{~cm}^{-1}$ for the obtained products is attributed to the $\mathrm{OH}$ stretching of the $\mathrm{Si}-\mathrm{OH}$ end groups in the PPMS chains, the appearance of this peak is due to the linkage between the released proton of Maghnite- $\mathrm{H}^{+}$and the oxygen atom at the end after the $\mathrm{D}_{3}^{\mathrm{Ph}, \mathrm{Me}}$ ring opening (Scheme $2 \mathrm{a}$ ), the decrease in its intensity with time of the reaction is clearly noticeable, which may be explained by the increase of polymerization degree leading to smaller number of $\mathrm{OH}$ chain ends. The small peak appears at about $3062 \mathrm{~cm}^{-1}$ is attributed to the C-H bond of the phenyl ring. The two bands at 2971 and $2925 \mathrm{~cm}^{-1}$ are respectively due to $\mathrm{C}-\mathrm{H}$ asymmetric/symmetric stretching of $\mathrm{CH}_{3}$. The two bands seen respectively at 2889 and $2843 \mathrm{~cm}^{-1}$ are assigned to the $\mathrm{C}-\mathrm{H}$ asymmetric/symmetric stretching of $\mathrm{CH}_{2}$. The small series of bumps at 1930, 1866, 1802 and $1757 \mathrm{~cm}^{-1}$ are caused by overtones (harmonics) of the phenyl ring vibrational modes having stretching frequencies in the fingerprint region. The bonds occur in pairs, one at $1601 \mathrm{~cm}^{-1}$ and one at $1483 \mathrm{~cm}^{-1}$ are due to the $\mathrm{C}=\mathrm{C}$ ring stretching absorptions. The signal at $1272 \mathrm{~cm}^{-1}$ is assigned to the $\mathrm{CH}_{3}$ symmetric deformation of $\mathrm{Si}_{-} \mathrm{CH}_{3}$. Peaks appearing at 1026, 1108 and $478 \mathrm{~cm}^{-1}$ are respectively attributed to the stretching vibrations and deformation vibrations of the linear Si-O-Si structures. The signal at $816 \mathrm{~cm}^{-1}$ is due to the Si-C stretching vibrations. The two bands at 734 and $688 \mathrm{~cm}^{-1}$ are assigned to the stretching vibrations of $\mathrm{C}-\mathrm{H}$ in the phenyl ring. The infrared spectrum of obtained PPMS using Maghnite- $\mathrm{H}^{+}$as catalyst revealed no differences from those obtained by other researchers $[30,31]$.

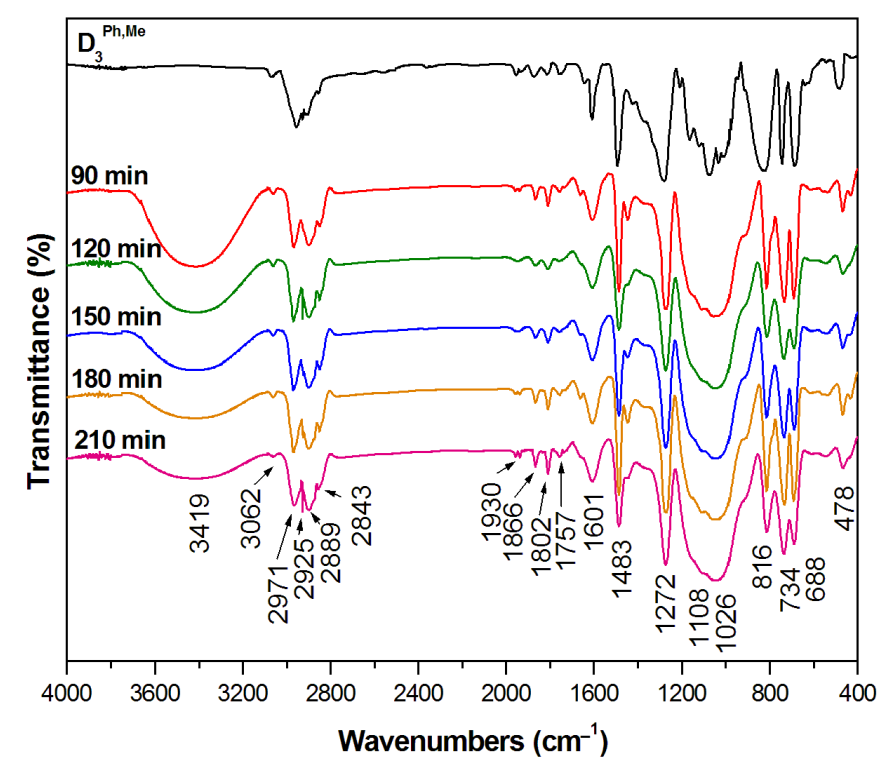

Fig. 2 IR spectra of PPMS obtained by the polymerization of $\mathrm{D}_{3}^{\mathrm{Ph}, \mathrm{Me}}$ at a temperature of $55^{\circ} \mathrm{C}$ for different times
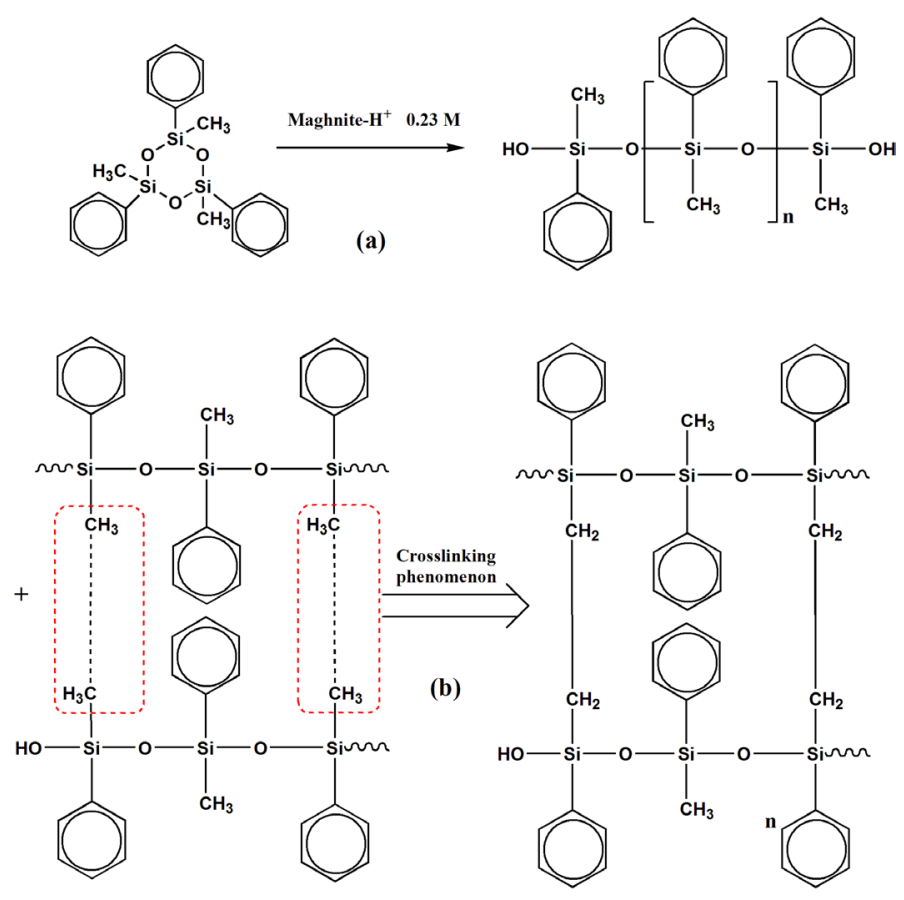

Scheme 2 Polymerization of $\mathrm{D}_{3}^{\mathrm{Ph}, \mathrm{Me}}$ by Maghnite- $\mathrm{H}^{+}$ 


\subsection{Proton Nuclear Magnetic Resonance (1H NMR)}

In order to identify more precisely the structure of the polymer obtained by the polymerization of $\mathrm{D}_{3}^{\mathrm{Ph}, \mathrm{Me}}$ using the Maghnite- $\mathrm{H}^{+}$as catalyst, the product was analyzed before and after reaction by NMR analysis by comparing the two spectra: that of the monomer and that of polymer obtained at $55^{\circ} \mathrm{C}$ for $150 \mathrm{~min}$. The results are shown in Figs. 3a and 3b, which shows the different chemical shifts. In both spectra, the dominant peak observed at about $1.19 \mathrm{ppm}$, is attributed to the methyl groups. The neighboring peaks at 6.81, 6.94 and 7.18 ppm are assigned to the protons of the phenyl ring. The small peak appearing at $4.81 \mathrm{ppm}$ is assigned to the $\mathrm{OH}$ groups at the ends of polymer chains during the reaction. Similar results were obtained by Fei et al. [32].
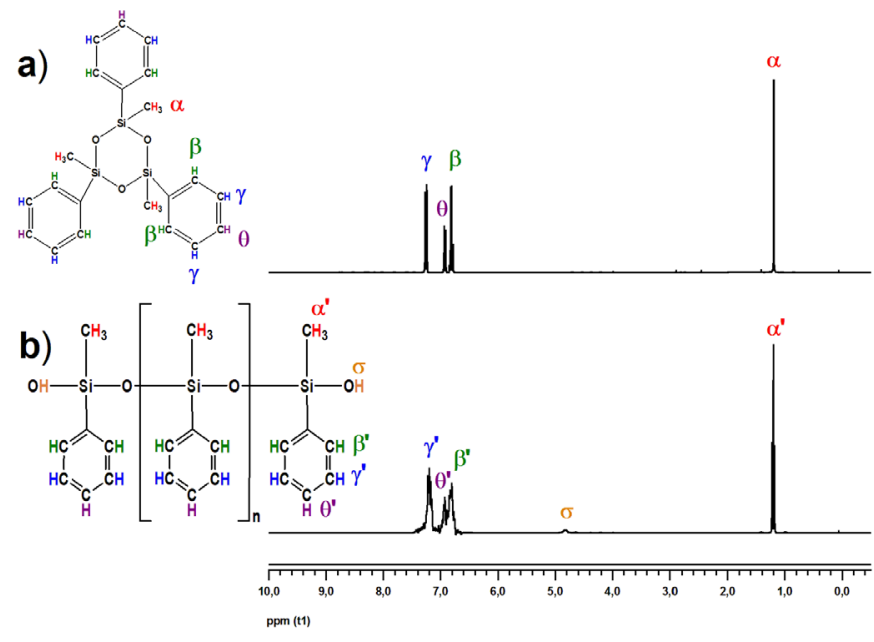

Fig. $3{ }^{1} \mathrm{H}$ NMR spectra of a) $\mathrm{D}_{3}{ }^{\mathrm{Ph}, \mathrm{Me}}$ and b) polymer obtained at a temperature of $55^{\circ} \mathrm{C}$ for $150 \mathrm{~min}$

\subsection{Carbon Nuclear Magnetic Resonance (13C NMR)}

It was therefore necessary to analyze the products obtained by ${ }^{13} \mathrm{C}$ NMR to provide a complement to the previous study. The results are shown in Fig. 4 (a, b and c) showing the ${ }^{13} \mathrm{C}$ NMR spectra of the monomer, the polymer obtained after $150 \mathrm{~min}$ and after $180 \mathrm{~min}$ respectively. The peak located at approximately $-0.12 \mathrm{ppm}$ for the monomer and $0.39 \mathrm{ppm}$ for the polymers corresponds to the carbon of $\mathrm{CH}_{3}$. The peaks at $137.85,130.39,128.76$ and $126.66 \mathrm{ppm}$ for the monomer, and at $137.96,131.44,128.77$ and $125.08 \mathrm{ppm}$ for the two polymers are assigned to the phenyl ring carbons as shown in Fig. 4.

Moreover, there is a creation of a down peak at $32.87 \mathrm{ppm}$ on the DEPT-135 spectrum of the polymer obtained after $180 \mathrm{~min}$, that is attributed to the carbon of $\mathrm{CH}_{2}$, indicating the formation of ethylene bridges between linear polymer chains (Scheme 2b). These results show that beyond $180 \mathrm{~min}$ of reaction time, the polymer chains can be crosslinked to form organopolysiloxane elastomers. a)

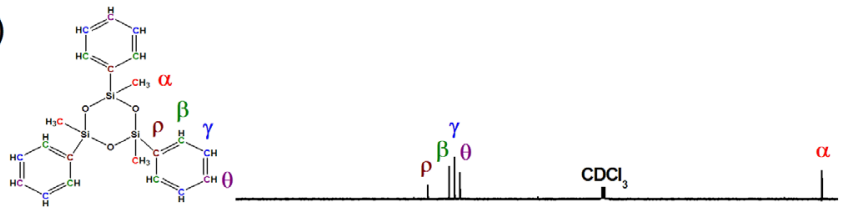

b)

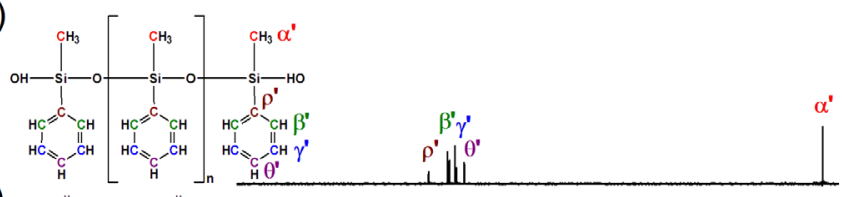

c)

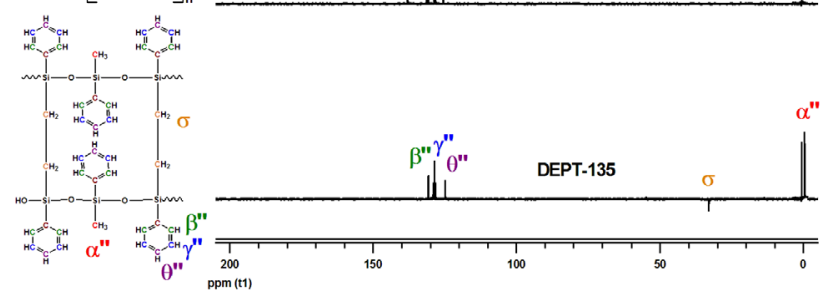

Fig. $4{ }^{13} \mathrm{C}$ NMR spectra of a) $\mathrm{D}_{3}^{\mathrm{Ph}, \mathrm{Me}}$, b) polymer obtained after $150 \mathrm{~min}$ and c) polymer obtained after $180 \mathrm{~min}$ at a temperature of $55^{\circ} \mathrm{C}$

\subsection{Differential Scanning Calorimetry (DSC)}

DSC was used as a thermal analysis, to identify and confirm at the same time the structure and the purity of the obtained product. Fig. 5 shows the DSC thermogram of the polymer obtained after $150 \mathrm{~min}$ of reaction time. The thermogram shows a small thermal deformation at about $-37.02{ }^{\circ} \mathrm{C}$, which corresponds to the glass temperature of the polymer $\left(\mathrm{Tg}=-37.02{ }^{\circ} \mathrm{C}\right)$, this $\mathrm{Tg}$ value is comparable to that of linear PPMS. The result obtained by DSC largely supports the results obtained by IR and NMR for the linear structure of the polymer obtained after $150 \mathrm{~min}$, it also simulates to a large extent the results obtained in previous research $[33,34]$.

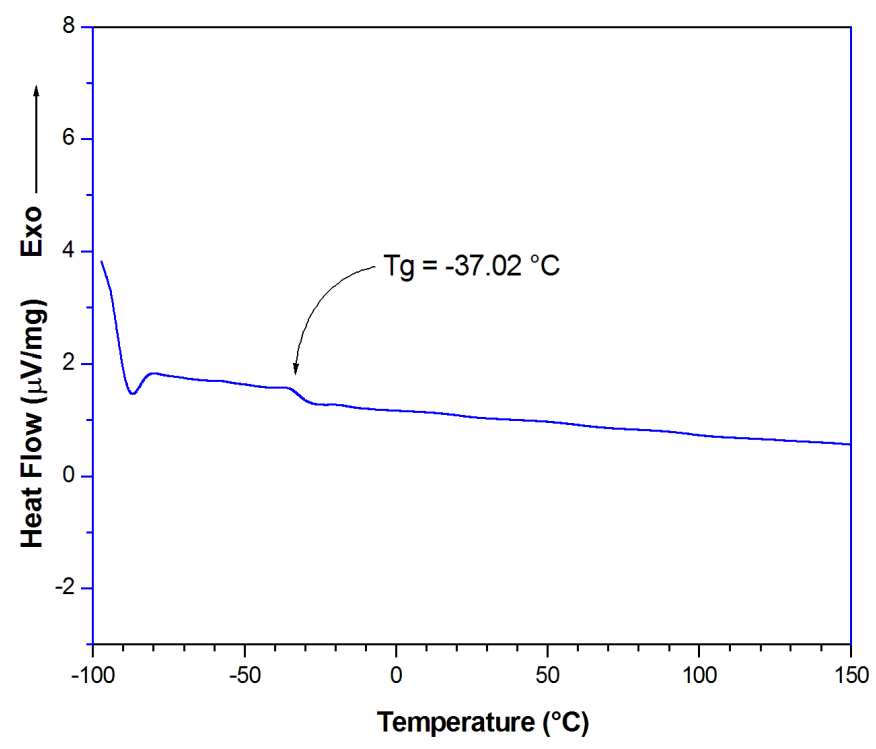

Fig. 5 DSC thermogram of obtained PPMS obtained after $150 \mathrm{~min}$ 


\subsection{Effect of temperature}

In an effort to understand and control more the polymerization reaction of $\mathrm{D}_{3}^{\mathrm{Ph}, \mathrm{Me}}$ catalyzed by Maghnite- $\mathrm{H}^{+}$, we have examined the effect of the temperature of the medium on the reaction that takes place there. Table 1 gives measured values of the monomer conversion and number average molecular mass of the polymers obtained in a temperature range of 40 to $70{ }^{\circ} \mathrm{C}$. Fig. 6 shows the gel permeation chromatograms of the polymers obtained at different temperatures. The increase in temperature leads to a significant increase in conversion reaching $88 \%$ at $55{ }^{\circ} \mathrm{C}$, beyond this temperature, this increase becomes negligible until the conversion stabilizes at its maximum at about $91 \%$. On the other hand, the variation in average molecular mass shows two different behaviors, a gradual increase from 40 to $55^{\circ} \mathrm{C}$, followed by a reduction after just exceed its highest value at about $55^{\circ} \mathrm{C}$, we assume that it is the ceiling temperature, this decrease in average molecular mass can be explained by the fragmentation of the chains suggests the thermal decomposition of PPMS after the breaking of Si-O bonds when approaching the boiling point. The thermal degradation phenomenon reflects a wide divergence between the molecular mass values, resulting in the increase of the polydispersity index, which is found in Table 1 .

Table 1 Effect of reaction temperature on $\mathrm{D}_{3}{ }^{\mathrm{Ph}, \mathrm{Me}}$ polymerization ${ }^{\mathrm{a}}$

\begin{tabular}{llll}
\hline $\mathrm{T}\left({ }^{\circ} \mathrm{C}\right)$ & $\begin{array}{l}\text { Conversion of } \\
\text { Monomer (wt \%) }\end{array}$ & $\mathrm{M}_{\mathrm{n}}(\mathrm{g} / \mathrm{mol})$ & $\mathrm{M}_{\mathrm{w}} / \mathrm{M}_{\mathrm{n}}$ \\
\hline 40 & 41 & 2650 & 1.06 \\
45 & 69 & 9425 & 1.08 \\
50 & 72 & 16248 & 1.12 \\
55 & 88 & 27514 & 1.13 \\
60 & 90 & 24347 & 1.55 \\
65 & 91 & 19998 & 1.74 \\
70 & 91 & 12478 & 1.91 \\
\hline${ }^{\mathrm{a}}{\mathrm{Maghnite-H^{+ } / \mathrm { D } _ { 3 } { } ^ { \text { Ph,Me } } \text { weight ration } = 1 . 5 \% . ~ R e a c t i o n ~ t i m e ~} 150 \mathrm{~min} .}$ & \\
$\mathrm{M}_{\mathrm{n}}:$ Number average molecular mass; & \\
$\mathrm{M}_{\mathrm{w}} / \mathrm{M}_{\mathrm{n}}:$ Polydispersity index. &
\end{tabular}

\subsection{Effect of Maghnite-H+/Monomer weight ratio}

In order to study the catalytic action of Maghnite- $\mathrm{H}^{+}$as a heterogeneous catalyst in the polymerization reaction of $\mathrm{D}_{3}^{\mathrm{Ph}, \mathrm{Me}}$, we performed the reaction with a catalyst content ranging from 0.5 to $2.5 \%$ by weight, so that for each catalyst content, the reaction time varied from 30 to $210 \mathrm{~min}$. The results of the influence of the Maghnite- $\mathrm{H}^{+}$content on the monomer conversion and on the number average molecular mass are shown in Fig. 7 and 8 respectively. In all tests, the reaction was carried out in bulk and at a temperature of $55^{\circ} \mathrm{C}$. It is clearly noticeable that for all the different Maghnite- $\mathrm{H}^{+}$contents, the reaction time has an effect proportionally positive on the monomer conversion before $180 \mathrm{~min}$. After this duration, the effect of reaction time has become negative (Fig. 7).

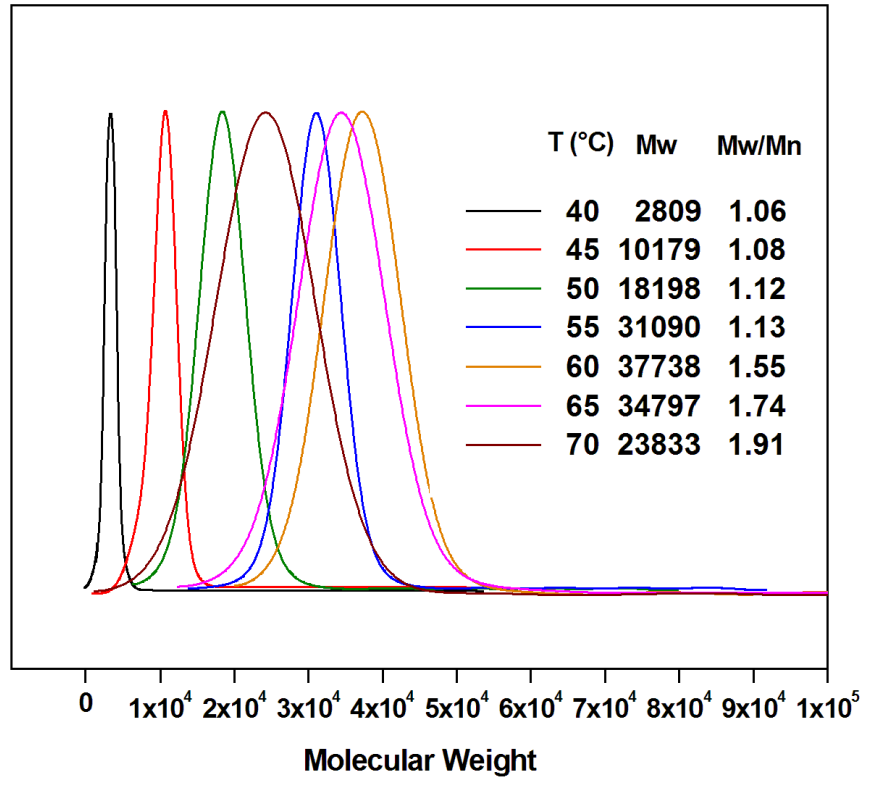

Fig. 6 Gel permeation chromatograms of the polymers obtained at different temperatures

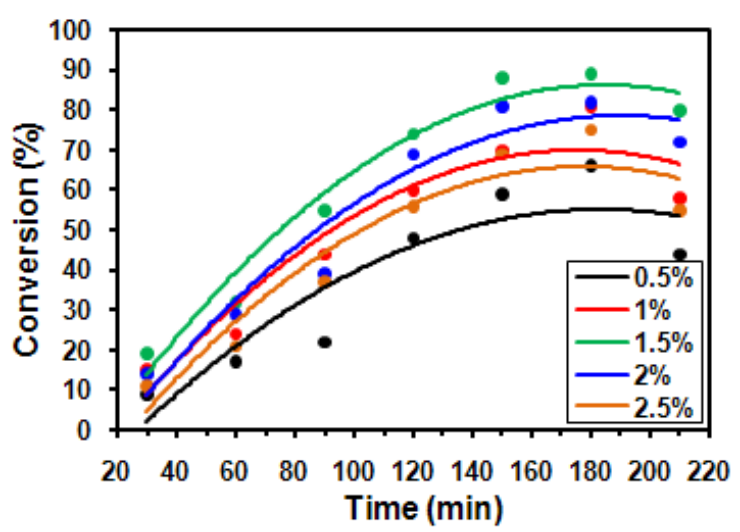

Fig. 7 Effect of Maghnite- $\mathrm{H}^{+} / \mathrm{D}_{3}^{\mathrm{Ph}, \mathrm{Me}}$ weight ratio on the conversion of monomer

The reduction in the monomer conversion for large periods may be explained by the occurence of depolymerization phenomenon of polymer chains caused by the active sites of the Maghnite- $\mathrm{H}^{+}$still remaining in the reaction medium. This result indicates that the Maghnite- $\mathrm{H}^{+}$can play the opposite role after periods of time sufficiently large. Similar results were obtained in previous studies $[7,8]$. On the other hand, the average molecular mass increases with increasing reaction time, the maximum value for the different Maghnite- $\mathrm{H}^{+}$contents is about $150 \mathrm{~min}$, then it stabilizes almost up to $180 \mathrm{~min}$, so that it begins to decrease. The reduction over time, of the peak corresponding to $\mathrm{OH}$ groups which exist only at the end of the polymer chains of PPMS synthesized by Maghnite- $\mathrm{H}^{+}$showing by the infrared analysis (Fig. 2), indicates that the chains became longer, resulting in large molecular mass. The temporary stabilization between 150 and $180 \mathrm{~min}$ of the average molecular mass is due to the crosslinking phenomenon, leading to branched structures because of the formation of ethylene bridges between the linear chains, this explanation is clearly supported by what has been 
obtained by ${ }^{13} \mathrm{C}$ NMR analysis (Fig. 4c). The decrease in the average molecular mass after $180 \mathrm{~min}$ can be explained by backbiting degradation in the growing polymer chains, which generates oligomers and cyclic polysiloxanes of varying sizes, thereby increasing the polydispersity index (Table 2).

Table 2 Kinetic evolution of $\mathrm{D}_{3}^{\mathrm{Ph}, \mathrm{Me}}$ polymerization ${ }^{\mathrm{a}}$ initiated by Maghnite- $\mathrm{H}^{+}$

\begin{tabular}{llll}
\hline Time (min) & $\begin{array}{l}\text { Conversion of } \\
\text { Monomer (wt \%) }\end{array}$ & $\mathrm{M}_{\mathrm{n}}(\mathrm{g} / \mathrm{mol})$ & $\mathrm{M}_{\mathrm{w}} / \mathrm{M}_{\mathrm{n}}$ \\
\hline 30 & 19 & 8557 & 1.02 \\
60 & 32 & 11470 & 1.04 \\
90 & 55 & 17488 & 1.05 \\
120 & 74 & 23478 & 1.08 \\
150 & 88 & 27514 & 1.13 \\
180 & 89 & 26666 & 1.17 \\
210 & 80 & 18524 & 1.31 \\
\hline
\end{tabular}

${ }^{\text {a }}$ Maghnite- $\mathrm{H}^{+} / \mathrm{D}_{3}{ }^{\mathrm{Ph}, \mathrm{Me}}$ weight ratio $=1.5 \%$. Reaction temperature $55^{\circ} \mathrm{C}$.

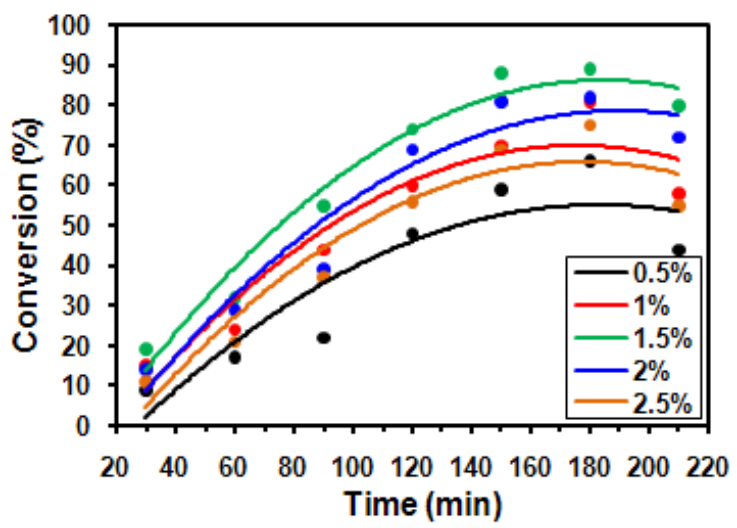

Fig. 8 Effect of Maghnite- $\mathrm{H}^{+} / \mathrm{D}_{3}{ }^{\mathrm{Ph}, \mathrm{Me}}$ weight ratio on the average molecular mass

\subsection{Kinetics of the polymerization reaction}

In order to study the chemical kinetics of the polymerization reaction of $\mathrm{D}_{3}^{\mathrm{Ph}, \mathrm{Me}}$ catalyzed by Maghnite- $\mathrm{H}^{+}$, we followed the evolution of the concentration of monomer over time, we were interested just for $\mathrm{t} \leq 180 \mathrm{~min}$, where there was not the depolymerization phenomenon. The results clearly indicate that the reaction is first-order with respect to monomer (Fig. 9).

\section{Conclusion}

Maghnite- $\mathrm{H}^{+}$showed an excellent catalytic capacity for the synthesis of polyphenylmethylsiloxane. The reaction was carried out under mild conditions and without the use of the solvent, Maghnite- $\mathrm{H}^{+}$was removed at the end of the reaction by simple filtration, which is largely in accordance with the principles of green chemistry.IR analysis confirmed the chemical structure of different polymers obtained, the presence of the $\mathrm{OH}$ group on the IR spectra indicates that they are linear polymers. NMR analysis showed that after a period of $150 \mathrm{~min}$, the polymer began to crosslink by establishing interchain bonds between the methyl groups attached to the silicon atom.

The study of the variation of the average molecular mass as a function of temperature informs us that the ceiling temperature of this polymerization is $55{ }^{\circ} \mathrm{C}$, beyond which the polymer can be depolymerized. The kinetic study demonstrated that the reaction is of the first order with respect to the monomer.

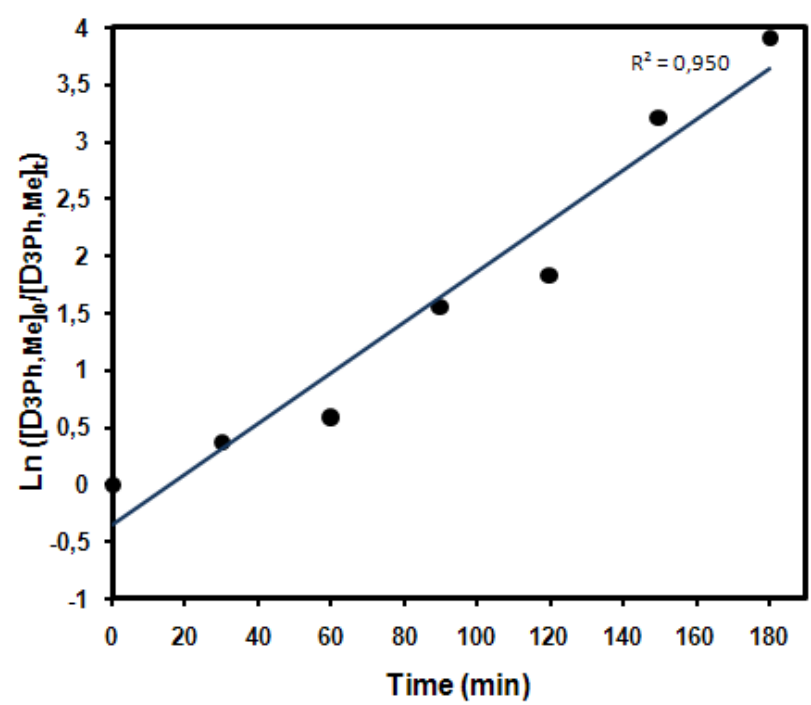

Fig. 9 First order kinetics for the polymerization of $\mathrm{D}_{3}^{\mathrm{Ph}, \mathrm{Me}}$ by Maghnite- $\mathrm{H}^{+}$ (In bulk, $\mathrm{T}=65^{\circ} \mathrm{C}$ and Mass content of catalyst $=1.5 \%$ )

\section{References}

[1] Clark, J. H., Rhodes, C. N. "Clean Synthesis Using Porous Inorganic Solid Catalysts and Supported Reagents." In: Journal of American Chemical Society Edition. (pp. 10-16). 2000.

[2] Belbachir, M., Bensaoula, A. US Patent. No 6, 274,527B1. 2001.

[3] Chen, B., Zhan, X., Yi, L., Chen, F. "Cationic Ring Opening Polymerization of Octamethylcyclotetrasiloxane Initiated by Acid Treated Bentonite." Chinese Journal of Chemical Engineering. 15(5), pp. 661-665. 2007. https://doi.org/10.1016/S1004-9541(07)60142-6

[4] Kherroub, D. E., Belbachir, M., Lamouri, S. "Preparation and Characterization of Organophilic Montmorillonite (12-maghnite) Using Algerian Clay." Oriental Journal of Chemistry. 30(4), pp. 1647-1651. 2004. https://doi.org/10.13005/ojc/300424

[5] Meghabar, R., Megherbi, A., Belbachir, M. "Maghnite- $\mathrm{H}^{+}$, an ecocatalyst for cationic polymerization of N-vinyl-2-pyrrolidone." Polymer. 44(15), pp. 4097-4100. 2003.

https://doi.org/10.1016/S0032-3861(03)00400-2

[6] Bouchama, A., Ferrahi, M. I., Belbachir, M. "Copolymerization of $\varepsilon$-Caprolactone with Tetrahydrofuran by a solid acid, in the Presence of Acetic Anhydride." Journal of Materials and Environmental Science. 6(4), pp. 977-982. 2015.

https://doi.org/10.13140/RG.2.1.2528.7201

[7] Kherroub, D. E., Belbachir, M., Lamouri, S. "Cationic Ring Opening polymerization of $\varepsilon$-caprolactam by a Montmorillonite Clay Catalyst." Bulletin of Chemical Reaction Engineering and Catalysis. 9(1), pp. 407-429. 2014.

https://doi.org/10.9767/bcrec.9.1.5555.74-80 
[8] Kherroub, D. E., Belbachir, M., Lamouri, S. "Study and Optimization of the Polymerization Parameter of Furfuryl Alcohol by Algerian Modified Clay." Arabian Journal for Science and Engineering. 40(1), pp. 143-150. 2015. https://doi.org/10.1007/s13369-014-1512-x

[9] Kherroub, D. E., Belbachir, M., Lamouri, S., Bouhadjar, L., Chikh, K. "Synthesis of Polyamide-6/Montmorillonite Nanocomposites by Direct In-situ Polymerization Catalysed by Exchanged Clay." Oriental Journal of Chemistry. 29(4), pp. 1429-1436. 2013.

https://doi.org/10.13005/ojc/290419

[10] Kherroub, D. E., Belbachir, M., Lamouri, S. "Nylon 6/clay nanocomposites prepared with Algerian modified clay (12-maghnite)." Research on Chemical Intermediates. 41(8), pp. 5217-5228. 2015. https://doi.org/10.1007/s11164-014-1623-8

[11] Kherroub, D. E., Belbachir, M., Lamouri, S. "Synthesis of poly(furfuryl alcohol)/montmorillonite nanocomposites by direct in-situ polymerization." Bulletin of Materials Science. 38(1), pp. 1-7. 2015. https://doi.org/10.1007/s12034-014-0818-3

[12] Kipping, F. S., Llyod, L. L. "Organic Derivatives of Silicon." Journal of the Chemical Society, Transactions. 79, pp. 449-459. 1901. https://doi.org/10.1039/CT9017900449

[13] Cusa, N. W., Kipping, F. S. "Organic derivatives of silicon. Part XLVII. cyclohexylphenyl and cyclohexyl derivatives." Journal of the Chemical Society. pp. 2205-2209. 1932. https://doi.org/10.1039/jr9320002205

[14] Rodriquez, F. "Principles of Polymer Systems." In: Hemisphere Publishing Corp Edition (pp. 589-594). 1989.

[15] DeGroot, J. V., Norris, A., Shedric, O. J., Clapp, T. V. "Highly transparent silicone materials." In: Proceedings of the SPIE Edition (pp. 116123). 2004.

[16] Polmanteer, K. E., Hunter, M. J. "Polymer composition versus lowtemperature characteristics of polysiloxane elastomers." Journal of Applied Polymer Science. 1(1), pp. 3-10. 1959. https://doi.org/10.1002/app.1959.070010102

[17] Gao, X., Wang, Q., Sun, H., Tan, Y., Zhang, Z., Xie, Z. "Nonequilibrium Anionic Ring-opening Polymerization of Tetraphenyltetramethylcyclotetrasiloxane (D4 $\left.{ }^{\mathrm{Me}, \mathrm{Ph}}\right)$ Initiated by Sodium Isopropoxide." Phosphorus, Sulfur, and Silicon and the Related Elements. 189(10), pp. 1514-1528. 2015. https://doi.org/10.1080/10426507.2013.860534

[18] Vardosanidze, Ts. N., Andrianov, K. A., Nogaideli, A. I., Yakushkiina, S. Ye., Rukhadze, N. P. "Anionic Polymerization of Stereoisomers of Tetramethyltetraphenylcyclotetrasiloxanes." Polymer Science USSR. 11(3), pp. 583-588. 1969. https://doi.org/10.1016/0032-3950(69)90043-4

[19] Kosfeld, R., Heb, M., Hansen, D. "Some Investigations on Structure and Physical Properties of Poly-(Dimethyl-Siloxane) and Poly-(MethyIPhenyl-Siloxane) Model-Networks." Polymer Bulletin. 3(11), pp. 603611. 1980.

https://doi.org/10.1007/BF01135331

[20] Chojnowski, J., Cypryk, M., Kazmierski, K. "Cationic Polymerization of a Model Cyclotrisiloxane with Mixed Siloxane Units Initiated by a Protic Acid. Mechanism of Polymer Chain Formation." Macromolecules. 35(27), pp. 9904-9912. 2002. https://oi.org/10.1021/ma021060n

[21] Sigwalt, P. "New Developments in Cationic Polymerization of Cyclosiloxanes." Polymer Journal. 19(5), pp. 567-580. 1987. https://doi.org/10.1295/polymj.19.567

[22] Molenberg, A., Möller, M. "A fast catalyst system for the ringopening polymerization of cyclosiloxanes." Macromolecular Rapid Communications. 16(6), pp. 449-453. 1995.

https://doi.org/10.1002/marc.1995.030160606
[23] Pibre, G., Chaumont, P., Fleury, E., Cassagnau, P. "Ring-opening polymerization of decamethylcyclopentasiloxane initiated by a superbase: Kinetics and rheology." Polymer. 49(1), pp. 234-240. 2008. https://doi.org/10.1016/j.polymer.2007.11.017

[24] Gee, R. P. "Emulsion polymerization of dimethylcyclosiloxane in cationic emulsion: mechanism study utilizing two phase liquid-liquid reaction kinetics." Colloids and Surfaces A: Physicochemical and Engineering Aspects. 481, pp. 297-306. 2015. https://doi.org/10.1016/j.colsurfa.2015.05.033

[25] Sun, C. N., Shen, M. M., Deng, L. L., Mo, J. Q., Zhou, B. W. "Kinetics of ring-opening polymerization of octamethylcyclotetrasiloxane in microemulsion." Chinese Chemical Letters. 25(4), pp.621-626. 2014. https://doi.org/10.1016/j.cclet.2014.04.013

[26] Sijiu, J., Teng, Q., Xiaoyu, L. "Kinetic study on the ring-opening polymerization of octamethylcyclotetrasiloxane (D4) in miniemulsion." Polymer. 51(18), pp. 4087-4094. 2010. http://dx.doi.org/10.1016/j.polymer.2010.06.038

[27] Conan J, T., William, P. W., Guoping, C. "Acid and base catalyzed ring-opening polymerization of 2,2,4,4,6,6-hexamethyl-8,8 diphenylcyclotetrasiloxane." Polymer. 44(15), pp. 4149-4155. 2003. https://doi.org/10.1016/S0032-3861(03)00373-2

[28] Chojnowski, J., Rubinsztajn, S., Fortuniak, W., Kurjata, J. "Oligomer and Polymer Formation in Hexamethylcyclotrisiloxane (D3)-Hydrosilane Systems Under Catalysis by tris(pentafluorophenyl)borane." Journal of Inorganic and Organometallic Polymers and Materials. 17(1), pp. 173187. 2007. https://doi.org/10.1007/s10904-006-9083-2

[29] Wilczek, K., Rubinsztajn, S., Chojnowski, J. "Comparison of the cationic polymerization of octamethylcyclotetrasiloxane and hexamethylcyclotrisiloxane." Macromolecular Chemistry and Physics. 187(1), pp. 39-51. 1986. https://doi.org/10.1002/macp.1986.021870104

[30] Zeng, J., Chen, J., Lin, Z., Chen, W., Chen, X., Wang, X. "Development of polymethylphenylsiloxane-coated fiber for solid-phase microextraction and its analytical application of qualitative and semi-qualitative of organochlorine pyrethroid pesticides in vegetables." Analytica Chimica Acta. 619(1), pp. 59-66. 2008. https://doi.org/10.1016/j.aca.2008.02.013

[31] Wang, C., Huang, Y. D., Wang, B. "Study on heat-resistant property of adhesive/carbon-carbon composites joints." International Journal of Adhesion and Adhesives. 26(4), pp. 206-211. 2006. https://doi.org/10.1016/j.ijadhadh.2005.03.003

[32] Fei, H. F., Xie, W., Wang, Q., Gao, X., Hu, T., Zhang, Z., Xie, Z. "Controlled synthesis and characterization of poly[methyl(3,3,3trifluoropropyl)siloxane] with selective and groups." RSC Advances. 4(99), pp. 56279-56287. 2014. https://doi.org/10.1039/C4RA12268B

[33] Clarson, S. J., Semlyen, J. A., Dodgson, K. "Cyclic polysiloxanes: 4. Glass transition temperature of poly(phenylmethylsiloxanes)." Polymer. 32(15), pp. 2823-2827. 1991. https://doi.org/10.1016/0032-3861(91)90115-Y

[34] Alig, I., Stieber, F., Wartewig, S. "Ultrasonic examination of the dynamic glass transition in amorphous polymers." Journal of Non-Crystalline Solids. 131(2), pp. 808-811. 1991. https://doi.org/10.1016/0022-3093(91)90685-y 